\title{
La Casa para destilar las aguas o Botica en el Monasterio del Escorial (Madrid, España)
}

\section{The House to distil essences or Apothecary in the Monastery of el Escorial (Madrid, Spain)}

\author{
$\underline{\text { P. Chías Navarro }}^{(*)}$, T. Abad Balboa ${ }^{(*)}$
}

\section{RESUMEN}

A pesar de su calidad arquitectónica, los edificios de servicio del Monasterio han sido poco estudiados. Entre ellos, la Botica o Casa para destilar las aguas merece una atención especial porque desde el punto de vista funcional resuelve el cierre suroccidental del Monasterio a través de la Galería de Convalecientes y el paso a la Compaña, y presenta un conjunto de soluciones constructivas singulares de gran interés. Sobre la base de la documentación histórica que se conserva, hemos datado las fases de construcción, hipótesis que se han confirmado a través de un levantamiento de precisión -hasta ahora inexistente- realizado por métodos directos y mediante un escáner láser.

Palabras clave: Historia de la construcción, Monasterio del Escorial, levantamiento arquitectónico, escáner láser, modelo 3D, siglo XVI.

\section{ABSTRACT}

Despite their architectural quality, the various service buildings surrounding the Monastery have gone almost unnoticed. Among them, the Apothecary or House to distil essences must be highlighted due to its functional solutions that link together the main building, the Gallery of Convalescents and the Compaña. Interest also arises from the construction methods and techniques, and the singular stonework. From the base of the $16^{\text {th }}$ century sources we drew and dated the construction processes and their contexts. Our hypotheses were then confirmed by the accurate survey produced for the first time using direct measuring techniques and a high definition scanner laser.

Keywords: History of Construction, Monastery of El Escorial, Architectural Survey, Scanner Laser, $3 D$ Model, 16th Century.

(*) Escuela de Arquitectura, Universidad de Alcalá (España).

Persona de contacto/Corresponding author: pilar.chias@uah.es (P. Chías Navarro).

ORCID: http://orcid.org/oooo-0001-6686-8820 (P. Chías Navarro); http://orcid.org/oooo-0001-9225-0709 (T. Abad Balboa).

Cómo citar este artículo/Citation: Chías Navarro, P.; Abad Balboa, T. (2019). La Casa para destilar las aguas o Botica en el Monasterio del Escorial (Madrid, España). Informes de la Construcción, 71(555): e298. https://doi.org/10.3989/ic.64642

Copyright: (C) 2019 CSIC. Este es un artículo de acceso abierto distribuido bajo los términos de la licencia de uso y distribución Creative Commons Reconocimiento 4.0 Internacional (CC BY 4.0). 


\section{INTRODUCCIÓN Y ANTECEDENTES}

El Monasterio de El Escorial constituye uno de los conjuntos arquitectónicos más relevantes del Renacimiento español desde su construcción por iniciativa del rey Felipe II entre 1563 y 1586. La singularidad y monumentalidad del edificio, unidas a la personalidad del fundador, han propiciado que las fuentes documentales sean extraordinariamente abundantes, pues numerosos cronistas, viajeros, literatos e investigadores lo han descrito o estudiado, dando lugar a una extensísima literatura con enfoques diversos, y a un importante corpus de dibujos.

Sin embargo, la mayoría de autores ha centrado su atención en el edificio principal del Monasterio y son muy pocos los que se han preocupado de los edificios de servicio circundantes, cuya calidad arquitectónica y sus soluciones espaciales y constructivas son en muchos casos excepcionales y destacables. Entre ellos, la Botica o "Casa para destilar las aguas", como la designó el gentilhombre de cámara Jehan Lhermite (1), no ha sido estudiada ni levantada con precisión hasta ahora a pesar de que merece una atención especial por su ubicación estratégica, su singularidad funcional y sus soluciones constructivas.

Desde el punto de vista de la situación, se encuentra en el exterior del cuadro o edificio principal del Monasterio, ocupando el ángulo suroeste a espaldas de la Galería de Convalecientes, y se conecta con el grupo de construcciones de la Compaña a través de una arquería (Figuras 1a,1b).

El edificio se ordena en torno a un patio o claustro de planta cuadrada, con la particularidad de carecer de pandas en los lados este y sur, que están ocupados respectivamente por el muro medianero con la vecina Galería de Convalecientes y por el cuerpo mediodía de la propia Botica. Por ello, dos de sus lados son muros casi ciegos. Estas peculiaridades serán objeto de análisis posteriormente.

Se compone de un sótano abovedado bajo el cuerpo sur, dos plantas -la baja al nivel de la plataforma del Jardín de los Frailes, y la primera a la cota de la planta baja del Monasterio o "al andar de la casa", y una tercera abuhardillada debajo de la cubierta.

Sólo la planta baja ha sido objeto de alguna atención previa debido a su adyacencia con la Galería de Convalecientes. Precisamente conocer las relaciones -o la ausencia de ellas- que se establecen entre las diferentes plantas de la Botica y de la Galería, así como entre aquélla, la Lonja y la huerta monacal, son imprescindibles para comprender el funcionamiento conjunto de ambos edificios en su entorno.

\subsection{Antecedentes}

Como detallaremos al hablar de las fuentes, desde la fundación del Monasterio hasta el siglo XIX escasearon las referencias a la Botica de cronistas y viajeros. En el siglo XX entre los estudios que se centran en la historia de la construcción del Monasterio la citan Andrés (2), Chueca Goitia (3), Kubler (4), Cervera Vera (5) y Bustamante (6). Con la excepción de este último, sus referencias concretas al edificio son muy escasas.

Análogamente, desde un punto de vista arquitectónico merecen señalarse los trabajos de Íñiguez (7), Zuazo (8) y Lorente Junquera (9), aunque su interés prioritario fue la contigua Galería y no la Botica. En consecuencia, los levantamientos que realizaron Zuazo y Lorente Junquera se redujeron a una planta muy simplificada al nivel del Jardín de los Frailesaportando prácticamente la misma información y reproduciendo los mismos errores-, y a la que este último añadió el alzado mediodía.

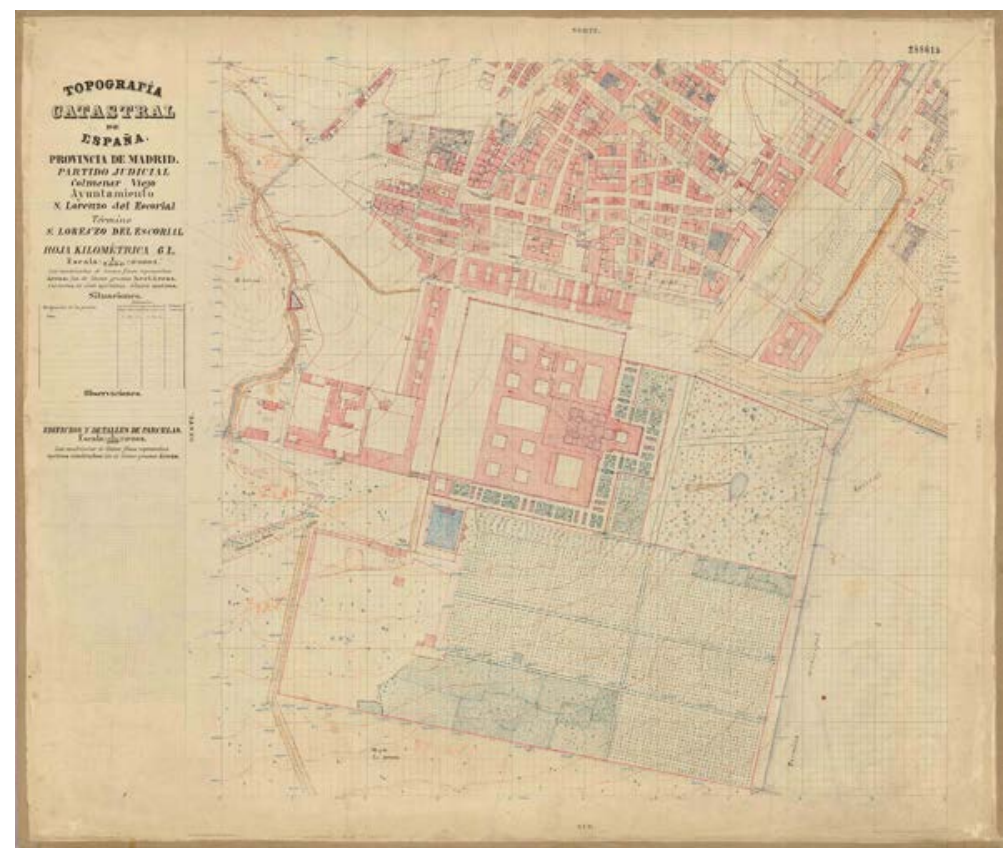

a)

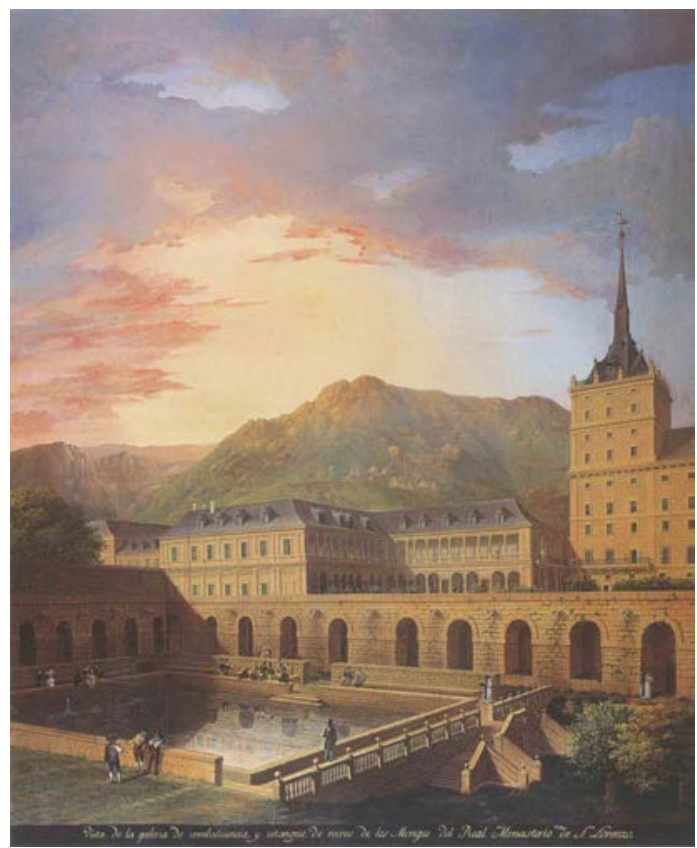

b)

Figura 1a. Instituto Geográfico y Estadístico, 1870: Topografía Catastral de España, San Lorenzo del Escorial, Hoja kilométrica 6L. Escala original 1:2.00o. El edificio de la Botica se sitúa cerrando el extremo mediodía de la Lonja oeste, frente al estanque de la huerta. Instituto Geográfico Nacional, Cartoteca Histórica.

Figura 1b. Fernando Brambilla 1822-1827: Vista de la galería de combalecencia y estanque de recreo de los Monges del Real Monasterio de El Escorial (sic). Patrimonio Nacional, Palacio de El Pardo. 
Los dibujos fueron realizados a escala pequeña, con poco detalle y escaso rigor métrico, por lo que los elementos arquitectónicos y los espacios no quedaron suficientemente definidos. Por otra parte, ninguno de ellos abordó los aspectos funcionales del conjunto ni su relación con el Jardín de los Frailes, con la huerta o con la Compaña.

Análogamente, en la bibliografía existente son muy escasas las referencias a asuntos importantes del diseño del entorno como puedan ser la topografía, la construcción de las infraestructuras que posibilitaron el funcionamiento del conjunto, o las relaciones que se plantearon entre ellas y con otras edificaciones de servicio del Monasterio. Estos aspectos esenciales para el sostenimiento de la vida cotidiana en el Monasterio han sido investigados recientemente por Chías y Abad $(10)(11)(12)(13)$.

\section{HIPÓTESIS Y OBJETIVOS}

La investigación se propone llenar este vacío en el conocimiento de la Botica al abordar el estudio de unas instalaciones que permitieron atender las necesidades del rey, de la corte y de la comunidad jerónima del Monasterio en cuanto a la producción de remedios, pomadas y destilados, a la vez que desarrollaba numerosos experimentos alquímicos con un éxito variable.

Para ello planteamos las siguientes hipótesis:

a) El edificio de la Botica fue el resultado de sucesivas decisiones que ampliaron el programa inicial.

b) A consecuencia de ello aumentaron las dimensiones previstas inicialmente de la Lonja oeste y de los muros de contención de tierras de la Lonja, de la plataforma del Jardín de los Frailes -Muro de los Nichos- y del camino de Robledo de Chavela.

c) Para adecuarse a lo ya construido se adoptaron algunas soluciones que resultan sorprendentes, y que se explican por la sucesión diacrónica de las fases de construcción de los distintos elementos.

En consecuencia, los objetivos propuestos son:

1. Obtener una documentación gráfica fiable y actualizada del edificio - hasta ahora inexistente- a través de un levantamiento de precisión.

2. Sobre la base del nuevo levantamiento, comprobar los aumentos de dimensión de los elementos construidos que permitan confirmar las hipótesis sobre la cronología y las fases de construcción del edificio.

3. Realizar análisis formales, funcionales y constructivos del edificio en relación con los adyacentes -Galería de Convalecientes, Lonja, Jardín de los Frailes, huerta y Compaña.

\section{METODOLOGÍA}

\subsection{Premisas iniciales}

El estudio de la Casa para destilar las aguas no se puede separar de los procesos de construcción de la vecina Galería de Convalecientes, del Muro de los Nichos y de la Lonja.

Ello se debe a que tanto la Botica como la Galería se apoyan sobre el Muro de los Nichos y forman parte de la solución para contener las tierras de la Lonja. Por otra parte, Botica y Galería comparten un muro medianero, y están comunicadas por varios accesos -dos en planta baja y dos en la planta primera. Actualmente el ático bajocubierta es un espacio único -resultado de la sustitución de las cubiertas originales de madera en los años 1950s-, por lo que no se ha utilizado para confirmar las hipótesis.

La unidad de medida original del edificio fue el pie castellano -equivalente a $0,2786 \mathrm{~m}-\mathrm{y}$ por ello todas las medidas se han tomado en pies castellanos y en metros.

\subsection{Las Boticas del Monasterio. Descripción de la Casa para destilar las aguas}

La botica monacal fue una tradición medieval también adoptada por la Orden Jerónima. Formaba parte de las dependencias de servicio que se agrupaban en conjuntos cerrados, claramente delimitados y separados de la vida cotidiana del monasterio, aunque próximos a las enfermerías u hospitales. Se completaban con un jardín medicinal, una huerta y una granja.

Las cinco enfermerías se abastecieron de las sucesivas boticas que en él existieron. En la zona conventual del Monasterio hubo dos: la primera se ubicó bajo la Torre del suroeste, junto al Claustro primero o de la Enfermería y con comunicación directa con la Galería de Convalecientes; sus instalaciones se completaron después con la construcción del nuevo edificio, cuya importancia llegó a ser tal que a finales del siglo XVI había alcanzado la categoría de tercera Farmacia Real junto a las dos existentes en Madrid. Por sus generosas dimensiones, capacidad y organización, fue de las más celebradas en la época.

En sus dependencias se destilaban esencias a partir de las plantas del jardín medicinal, y se elaboraban y almacenaban los medicamentos, como confirma el Libro de Costumbres del Real Monasterio de San Lorenzo el Real: "el boticario coge a su tiempo las hierbas, semillas, raíces y cosas que ha menester para su botica y pónelas a secar y guárdalas para su uso ..." (14).

Las descripciones del Doctor Almela (15) arrojan luz sobre sus distintas dependencias u "oficinas" y su contenido en el siglo XVI: "[La Botica] es grande y muy hermosa, y aseada y limpia, y cumplida de todo género de medicinas como son jarabes, y aguas, aceites y ungüentos, emplastos y confecciones de laxativos, y lectuarios, y conservas, y antídotos, y tabletas y polvos, y otras varias medicinas". En cuatro de las seis piezas de la planta baja se hacían jarabes e infusiones y se sacaban zumos y aceites esenciales; las otras dos se utilizaban para almacenar herramientas, vasos y hierbas.

En la primera planta al nivel del "andar de la casa" había otras siete oficinas: una para las aguas destiladas, y otra con dos 'baños de maría' con seis alambiques y un evaporatorio que constaba de treinta y dos alambiques. La tercera dependencia contenía prensas y morteros, y en la cuarta estaban "los hornos para el arte clínica donde se sacan quintaesencias y se hace oro potable y cualquier otro metal y piedras”. En la quinta oficina estaban "las aguas primeras que dan los materiales de que se sacan las quintaesencias", mientras la sexta y la séptima eran dos grandes aposentos que contenían respectivamente dos chimeneas y un evaporatorio de ciento veinte alambiques de vidrio "que es la gran máquina de Matiolo". 
La citada descripción de Lhermite, aunque menos prolija coincide con la de Almela y añade unos dibujos de los principales aparatos que justifican el diseño, dimensiones e instalaciones de las salas.

En el Sumario publicado por Juan de Herrera en 1589 (16), explicaba los grabados que había realizado con Pedro Perret para difundir la magna empresa del Escorial. En el texto que acompaña al Primer diseño o planta baja se explica: "V VV. Botica y hueco de la torre de este ángulo, y fuera de estas dos piezas tiene otras muchas bóvedas de grande servicio, y ultra de estas, arrimado al muro del corredor de enfermos por la parte XX. al Poniente se ha hecho un patio con tres cuartos todo para el servicio de la Botica donde hay destilaciones y cosas de este oficio, y por allí hay un paso desde el convento a la casa de la Compaña, pero por no caber en este papel no se hizo el diseño en la lámina. / XX. Corredor de sol para convalecientes que se comunica con la botica nueva ya dicha”, haciendo referencia a la aneja Galería de Convalecientes -también llamados Corredorcillos del sol-, y al nuevo edificio de la Botica.

Esta segunda Botica construida fuera del cuadro entre 1585 y 1592, es el objeto de la presente investigación.

\subsection{Las fuentes escritas}

Entre las fuentes contemporáneas a la construcción que describen el conjunto monacal, hay que destacar en primer lugar la documentación original y los contratos de obra que se conservan en la Real Biblioteca del Monasterio del Escorial (en adelante, RBMSLE) y en la Biblioteca y Archivo del Palacio Real de Madrid (en adelante BPR y AGP, respectivamente). Esta documentación manuscrita resulta particularmente relevante porque detalla las condiciones en las que los distintos oficios y laborantes debían ejecutar los diferentes trabajos de construcción, y porque algunos aún contienen trazas originales (17) que, unidas a las que se han segregado y se conservan en la BPR y en otros archivos, permiten reconstruir los procesos de construcción y sus circunstancias, y datar muchos de los elementos de la Botica.

Otro grupo de fuentes no menos interesantes lo constituyen las obras manuscritas de los cronistas contemporáneos, destacando las de fray Juan de San Jerónimo (18) y fray José de Sigüenza (19), así como las ya citadas del Doctor Almela y de Jehan Lhermite.

Los viajeros de los siglos posteriores alabaron los jardines, pero apenas prestaron atención a los edificios de servicio ni a la Botica. Fueron excepciones Wadsworth (20) y Fanshawe (21) en el siglo XVII, y Ponz (22) en el XVIII, que aportaron valiosas informaciones sobre el funcionamiento del edificio, el mobiliario, el botamen y su estado de conservación.

En el siglo XIX pocos viajeros se detuvieron a pasear por la Botica, aunque la mayoría visitaron los jardines y la Galería. Los que la recorrieron en la primera mitad del siglo presentaron una imagen romántica del edificio, pero paulatinamente fueron abriéndose paso visiones más objetivas, destacando entre ellas las descripciones de las guías de viaje. Al primer grupo pertenecen Álvarez (23), Ford (24), Quevedo (25) y Rotondo (26), y entre las guías hay que citar a Bermejo (27) y a Ramírez y La Guardia (28).

Para conocer los usos que albergó la Casa para destilar las aguas y el contexto de la Medicina y la Farmacia del siglo XVI en España, ha sido necesario investigar sobre Medicina, Iatroquímica, Botánica, Terapéutica y enfermedades en la Corte de Felipe II y en el propio Monasterio. Las dolencias del rey han quedado recogidas en la numerosa correspondencia que se conserva en el Archivo del Instituto de Valencia de Don Juan y en el Archivo Zabálburu, ambos en Madrid, y en la British Library de Londres, sección Additional Manuscripts.

Las principales epidemias padecidas entonces en la comarca de San Lorenzo han quedado registradas en varios documentos custodiados en el Archivo Histórico Municipal de El Escorial, y en las Memorias Sepulcrales del Monasterio, que reflejan con exactitud las causas de fallecimiento de todos los monjes del mismo, siendo las principales la gota o "mal de piedra", la peste, el tabardillo, romadizo y gripe, el "dolor de costado" o "mal de la muerte", la tuberculosis, las afecciones febriles como el paludismo, y los accidentes.

Sobre la base de estos precedentes, Chías (29) elaboró una primera aproximación al estudio de la Botica en el que ya se apuntaban algunos aspectos que hemos verificado con el levantamiento de precisión, como exponemos en el presente trabajo.

\subsection{Las fuentes gráficas: análisis y comparación con la realidad construida}

Aunque son muy numerosos los cuadros, dibujos y grabados en los que aparece la Botica (30), en este estudio sólo hemos considerado los que pueden aportar datos constructivos o métricos.

Entre las fuentes gráficas contemporáneas a la construcción del edificio se encuentra la citada serie de doce Estampas de Herrera y Perret, dibujada entre 1583 y 1589. El Primer diseño muestra la Galería e indica la ubicación de la Botica. Ambas están también representadas en el Sexto y el Séptimo diseño, pero la falta de correspondencia entre los grabados y la realidad construida es evidente.

El Sexto diseño corresponde al alzado sur del Monasterio, y en su explicación se puede leer: "F.G. Corredor de enfermos, que mira al Mediodía, y consecutivo a él hacia la parte de Poniente hay un patio con tres cuartos que todo él sirve para servicio de la botica, y para destilaciones y otras cosas de esta profesión, no se ha puesto en este diseño, ni en la planta, porque no cabía” (31). De nuevo, el dibujo se interrumpe en el muro medianero de la Galería con la Botica (Figura 2).

Efectivamente la Galería está rotulada como F y G sobre la limatesa de cubierta, y muestra como R la pasarela exterior de comunicación entre la Torre de la Botica y la planta primera de la Galería. Pero el dibujo también evidencia varias contradicciones claras con la realidad construida.

En primer lugar, el frente mediodía de la cubierta no es triangular porque se le adosó el edificio de la Botica; además el testero sur de la Galería muestra ya un diseño muy próximo al definitivo que se integrará perfectamente en el alzado final del conjunto -aunque para ello hubiera que incorporar ventanas esviadas e incluso falsas.

En segundo lugar, el faldón de cubierta bajo G se construyó inclinado, y tampoco coinciden las ventanas de las buhardillas. 


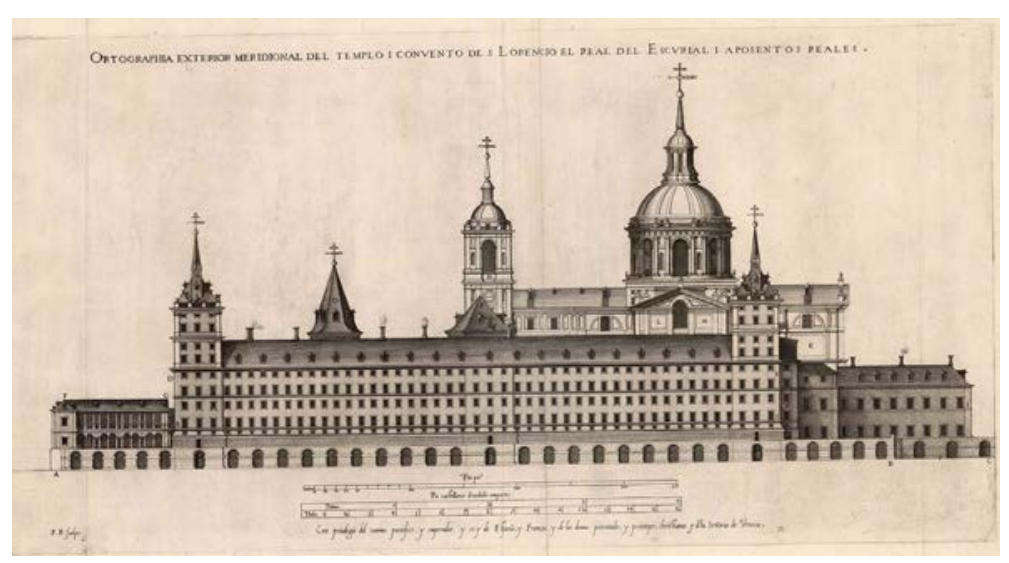

a)

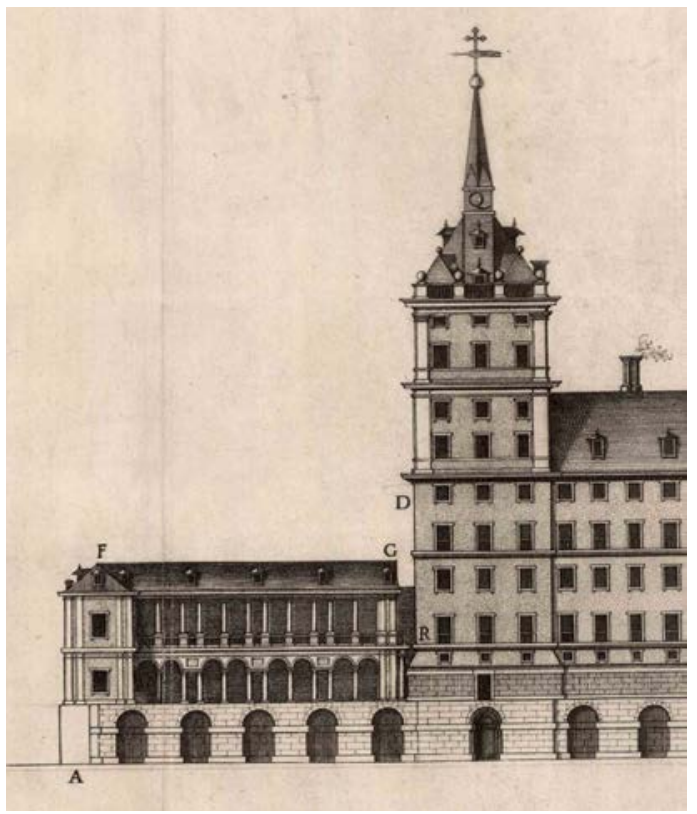

b)

Figura 2. Juan de Herrera y Pedro Perret, 1587: Sexto diseño. Ortographia exterior meridional del Templo i Convento de S. Lorencio el Real del Escurial i Aposentos Reales. (a) Alzado mediodía. (b) Detalle de la Galería de Convalecientes o Corredorcillos del Sol. BPR, Signatura IX-M-243 (6).

En tercer lugar, el pórtico que cierra la panda orientada al sur y que recibe a la pasarela volada desde la Torre fue una solución posterior, como se aprecia en la trabazón de las fábricas y en la inmediatez del peto de la escalera hacia la huerta -no representado por Herrera.

Por último, A define la sección del muro de contención de los nichos, pero éste no se levantó en este punto sino $84^{1 / 3}$ pies castellanos más al oeste, desplazándose y prolongándose para formar el basamento del nuevo edificio.

Como parte de la serie, el Séptimo diseño es una perspectiva aérea del Monasterio desde el oeste en el que el edificio de la Botica figura en el ángulo inferior derecho (Figura 3).

Como en el Sexto diseño, la diferencia entre perspectiva y realidad es evidente, no sólo en las cubiertas -que finalmente

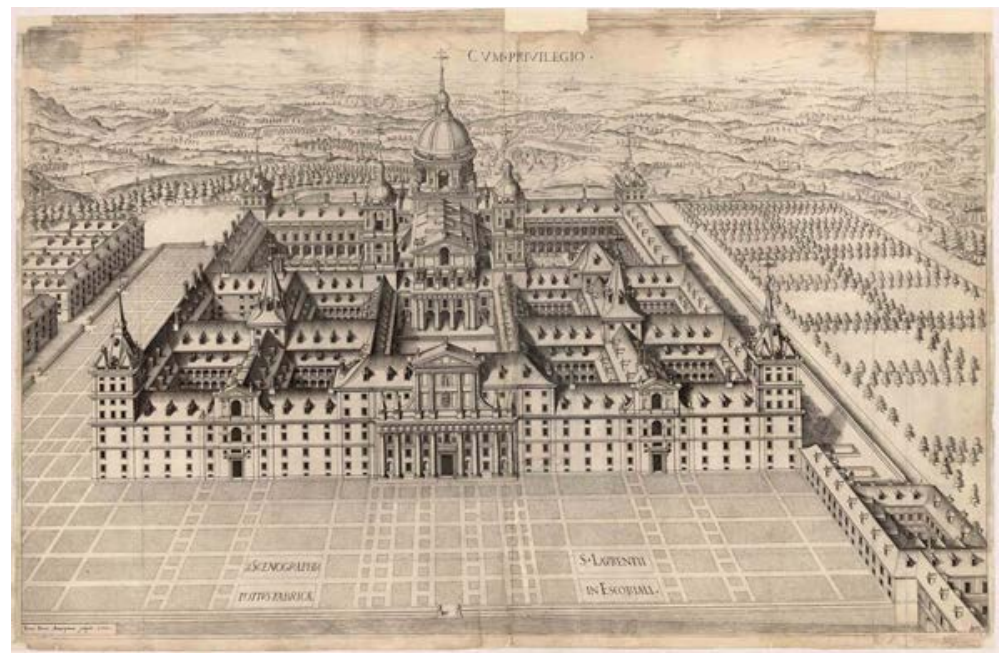

a) añadieron faldones de plomo al incorporarse las pandas norte y oeste del claustrico-, sino porque el dibujo muestra un diseño de los muros interiores sur y este de aquél que luego se construyeron prácticamente ciegos: el oriental (Figura 3b) aparece como una galería con vanos adintelados enmarcados por una falsa arquería, motivo que se repite en el muro sur. Sin embargo, una atenta inspección del grabado permite

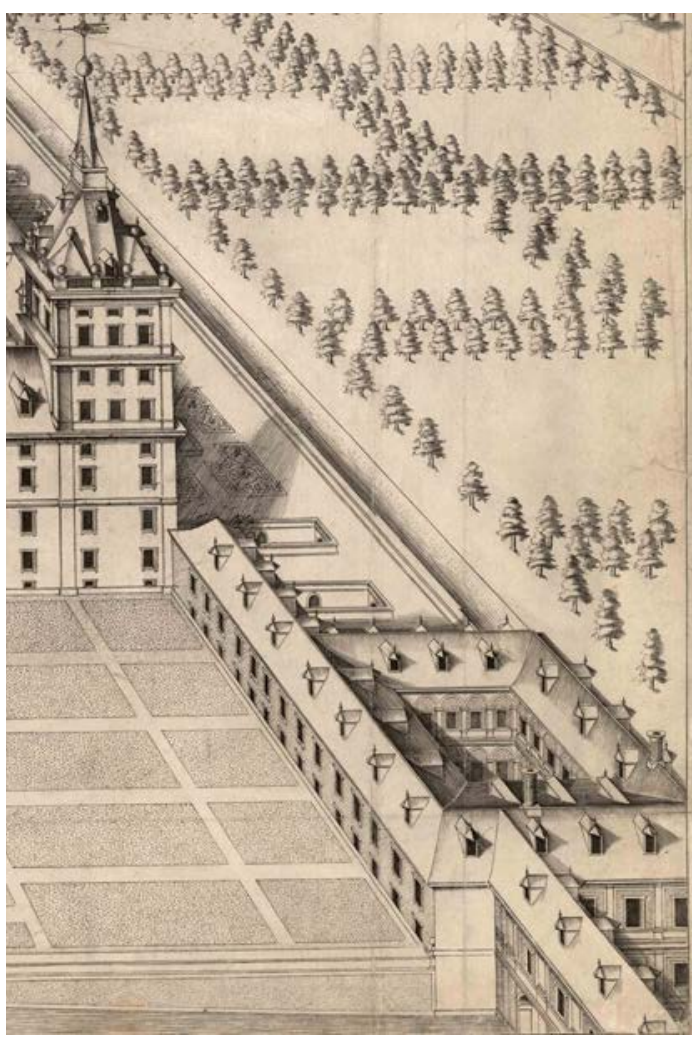

b)

Figura 3. Juan de Herrera y Pedro Perret, [1587]: Séptimo diseño. Scenographia S. Laurentii Totius Fabricae in Escuriali. (a) Perspectiva desde poniente. (b) Detalle de la Torre, los jardines, la Botica y el paso a la Compaña. BPR, Signatura IX-M-243 (7). 
apreciar que el rayado interior de las ventanas tiene distinta intensidad en ambos alzados interiores que no se debe a la incidencia de la luz. La hipótesis que planteamos es que en el proyecto del muro oriental se había propuesto una serie de ventanas fingidas tanto en la planta baja como en la primera -muy frecuentes en el resto del Monasterio por razones compositivas-, que debían haberse superpuesto, a modo de falsa fachada, al muro de sillarejo existente, pero que no llegaron a realizarse. En cambio, el alzado mediodía simplemente quedó sin terminar, habiéndose construido dos puertas en la planta inferior -hoy cegadas pero visibles-y dos ventanas en la superior.

El dibujo tampoco representa las chimeneas que, partiendo del sótano de la Galería suben hasta la cubierta a la altura de las buhardillas pero manteniéndose en el faldón interior de la cubierta para evitar que los malos olores alcanzaran el Monasterio (32).

Se conserva también otro dibujo fechado a finales del siglo XVI atribuido a Francisco de Mora, que sucedió a Herrera en la dirección de las obras del Monasterio y diseñador del edificio de la Botica (Figura 4).

Consiste en una planta de conjunto que representa la huerta y el estanque grande, cerrados por el norte y el oeste por los distintos tramos del Muro de los Nichos, los jardines pensiles, la Botica y la Galería de Convalecientes -que ya muestra las columnas de su testero oriental tangentes al pretil de la escalera a la huerta-, y por la fachada sur del Monasterio. El dibujo resulta particularmente interesante porque representa la planta al nivel del jardín de Galería y Botica; pero ésta, en lugar de organizarse en torno a un patio, tiene forma de $\mathrm{L}$ y está abierta hacia el mediodía.

Probablemente represente la primera solución que se pensó para el edificio -ya que la L corresponde exactamente a los dos lados del claustro que tienen pandas con arquerías-, que posteriormente se completó con el cuerpo sur. La hipótesis resulta aún más plausible si se tiene en cuenta que, debido a las reducidas dimensiones definitivas del claustro $-5^{8^{1 / 5}}$ x $58^{1 / 4}$ pies en la parte no cubierta- no hubiera sido posible incorporar pórticos en sus otros dos lados porque habría quedado un espacio libre central excesivamente pequeño.
Tampoco se podía haber extendido el edificio hacia poniente porque hubiera invadido el camino a Robledo.

El siguiente levantamiento en el que aparece la Casa para destilar las aguas se realizó a mediados del siglo XVIII, y por su calidad y precisión ha sido de gran utilidad para comprobar el estado de cubiertas y fachadas. Se trata del levantamiento llevado a cabo por iniciativa del Conde de Aranda,dirigido por José de Hermosilla y realizado por los ingenieros Bécaud y Fillera en 1759 (33)(34) con una notable precisión métrica.

\subsection{Métodos utilizados en el levantamiento y la redacción de los planos}

El levantamiento del conjunto de los edificios de la Galería, la Botica y el correspondiente sector del Muro de los Nichos se ha realizado a lo largo de varias campañas entre los años 2015 y 2018.

En una primera fase realizamos una primera medición directa y elaboramos los correspondientes croquis de campo. Asimismo identificamos los elementos arquitectónicos más interesantes y valoramos las estrategias a seguir en las etapas sucesivas. El levantamiento se realizó con dos escáneres Leica: un equipo P40 con un alcance de $60 \mathrm{~m}$ y un BLK 360 con un alcance de $40 \mathrm{~m}$, ambos con cámaras integradas de alta resolución. Debido a su manejabilidad y peso reducido, el segundo equipo se ha utilizado preferentemente para el levantamiento de los interiores.

A la hora de planificar el escaneado decidimos: 1) incorporar el sótano de la Galería de Convalecientes para poder corroborar las hipótesis y analizar las interconexiones; 2) resolver la diferencia de cotas y la posible falta de intervisibilidad entre puntos de estación identificando varios puntos visibles desde estaciones distintas.

Una vez concluido el trabajo de campo se procesaron los datos en gabinete. Para agrupar las nubes de puntos de las

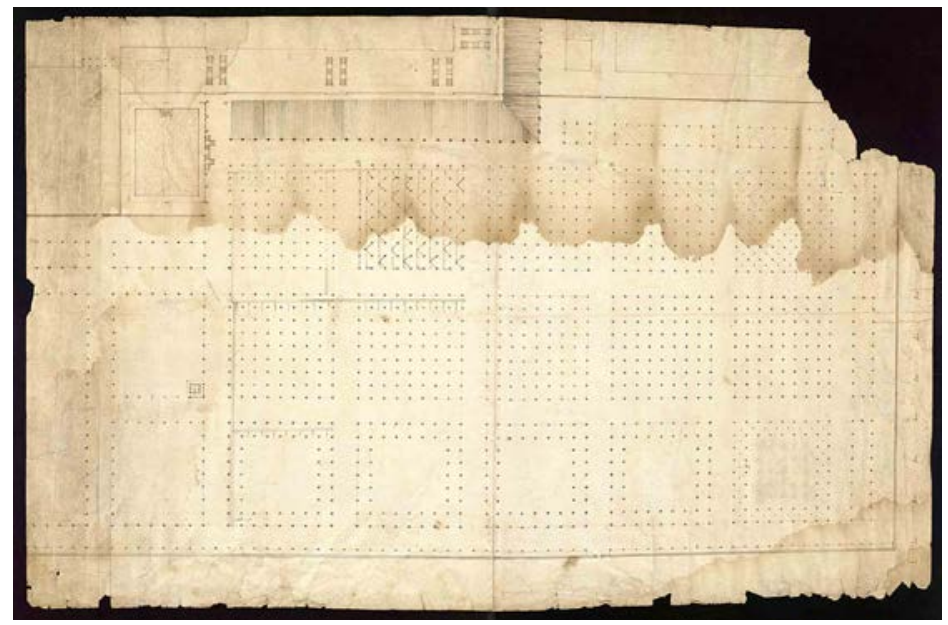

a)

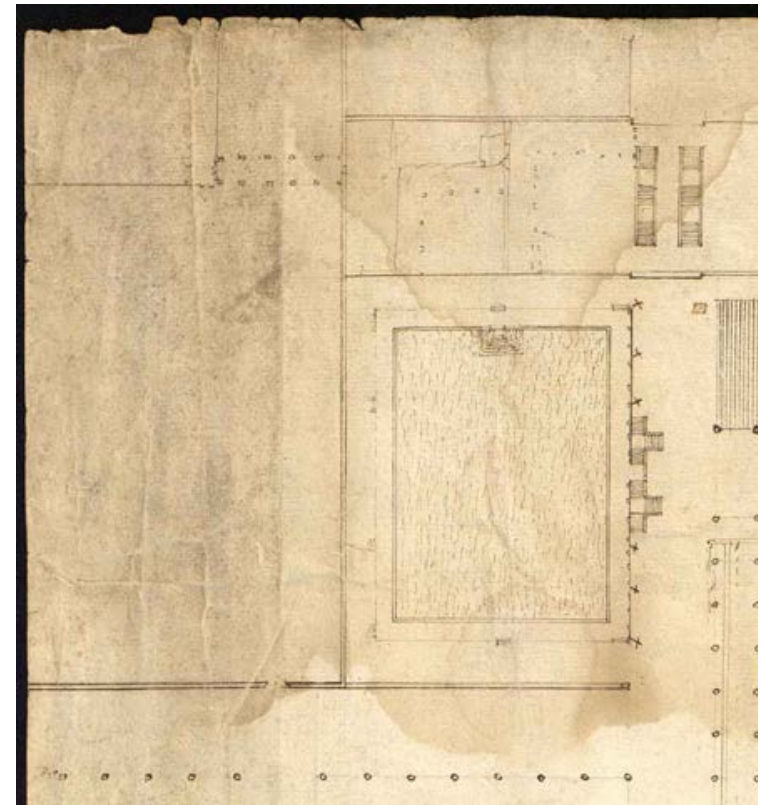

b)

Figura 4. Francisco de Mora, c.1585: Plano de la huerta del Monasterio de San Lorenzo de El Escorial. (a) Planta completa. (b) Detalle del ángulo superior izquierdo. Archivo Histórico Nacional, Madrid, Mº de Exteriores, MPD.157. 

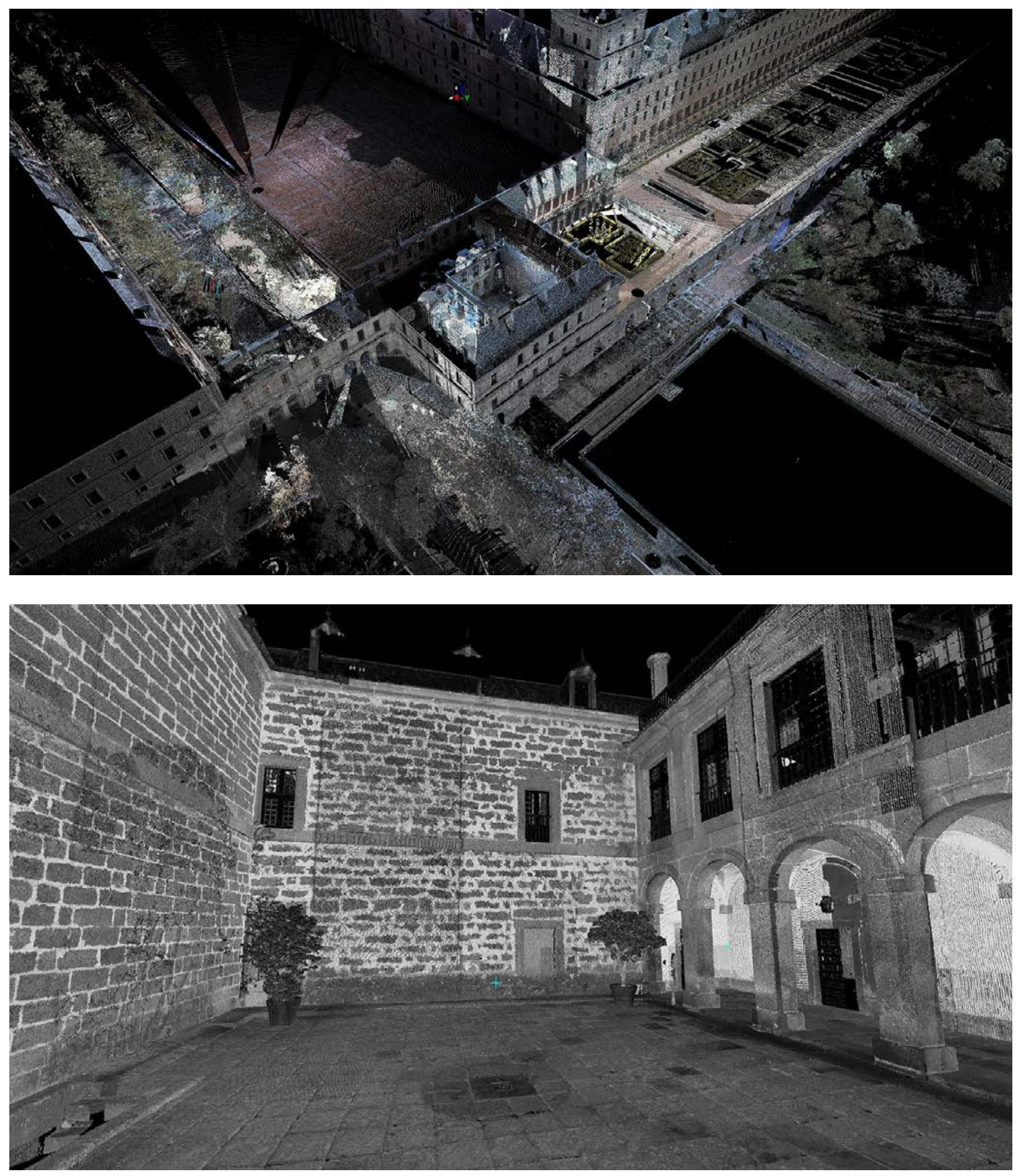

Figura 5. Pilar Chías y Tomás Abad, 2017: Modelo 3D del conjunto y detalle del claustro de la Botica.

distintas campañas utilizamos el programa Cyclone de Leica: primero las correspondientes a las capturas exteriores, incorporando sucesivamente los interiores hasta componer el modelo 3D (Figura 5).

El modelo se ha exportado a Autocad por medio de un módulo integrado. Hemos dibujado el edificio a escala 1:50 porque permite mostrar un importante nivel de detalle, esencial para la comprensión de determinadas soluciones de diseño, lo que no hubiera sido posible a escalas menores.
La nueva documentación gráfica manifiesta claramente que la diferencia de cotas entre el "andar de la casa" y el Jardín es de 18 pies, y de 36 respecto a la base del Muro de los Nichos. Pero también evidencia el importante espesor de los muros interiores, exteriores y medianero, llegando a alcanzar los 8 pies el que contiene las tierras de la Lonja, o los 12 pies si se incluyen los contrafuertes (Figura 6).

Actualmente estamos dibujando con detalle otros elementos singulares de interés -escaleras y bóvedas y sus despieces, 

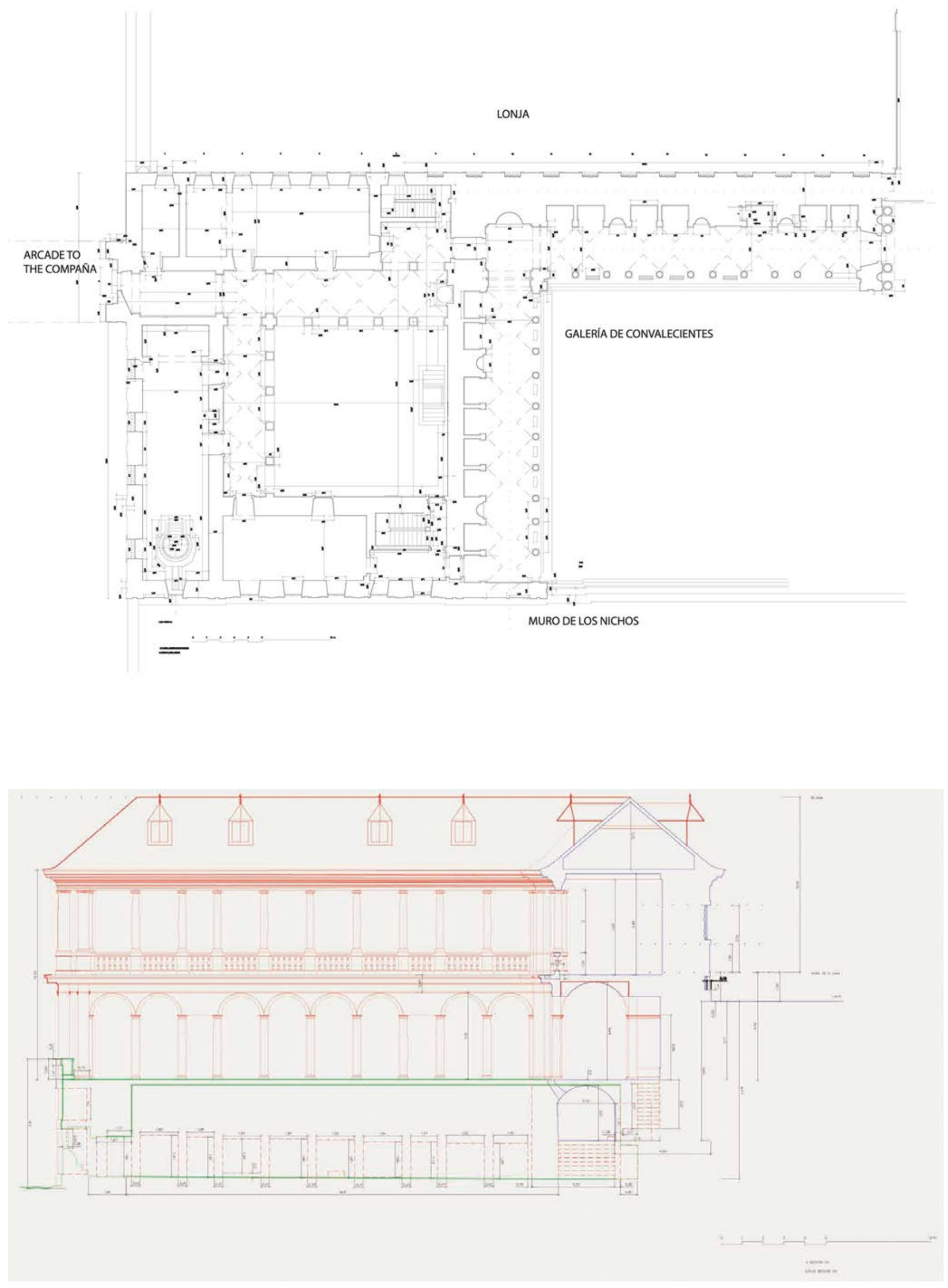

Figura 6. Pilar Chías y Tomás Abad, 2017: a) Planta del conjunto al nivel del Jardín de los Frailes. b) Secciones acotadas de la Galería de Convalecientes. En azul: sección del nivel superior de los sótanos de la Galería; en verde: sección longitudinal del nivel inferior; en rojo aparece proyectado el alzado este. Escala original, 1:50. 

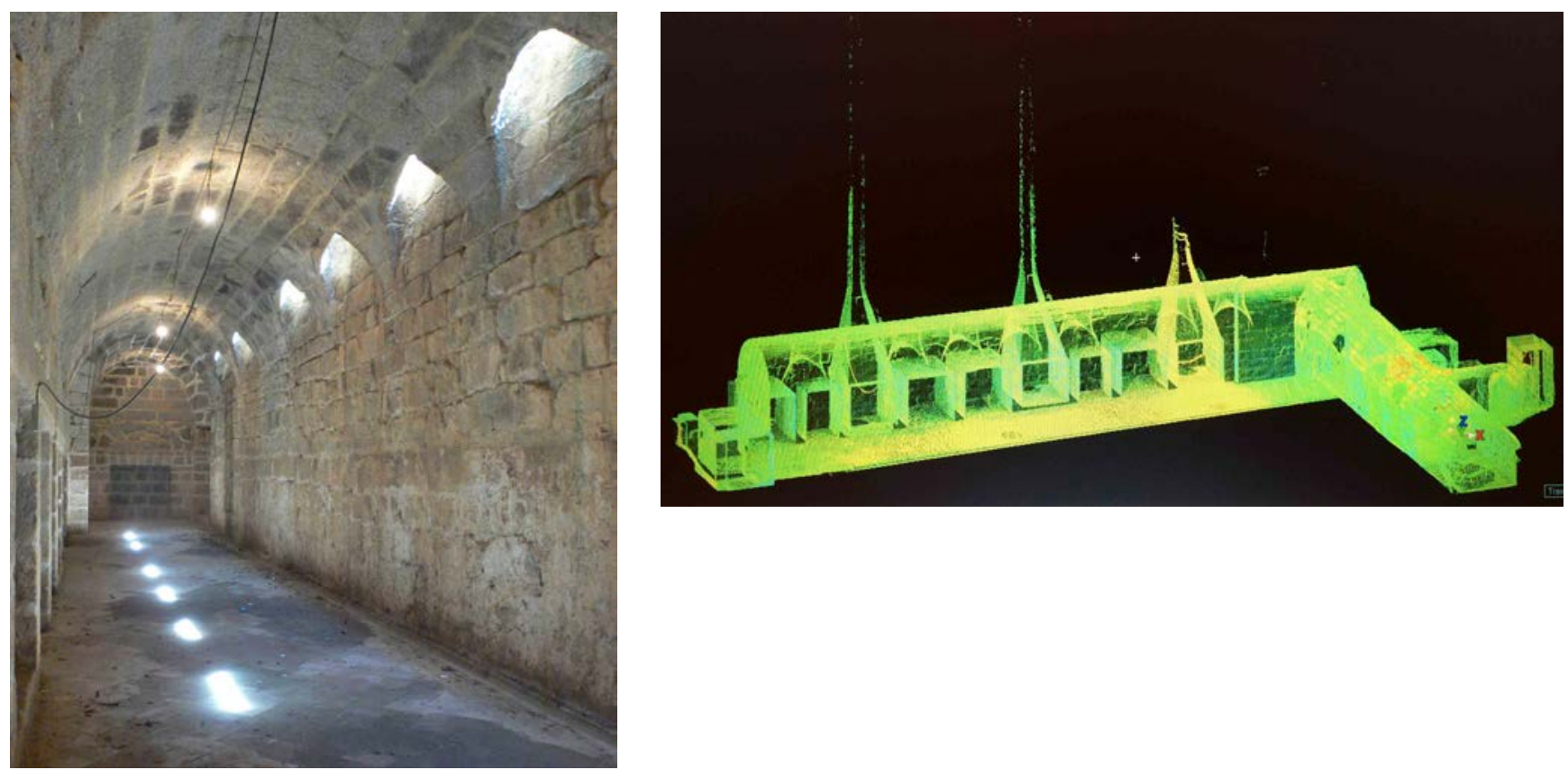

Figura 7. Sótano de la Galería situado bajo la panda orientada al este.

entablamentos y cornisas, capiteles, y determinadas soluciones singulares de estereotomía (Figura 7).

\subsection{Cronología del conjunto estudiado}

En paralelo al trabajo de campo estudiamos la cronología de la obra analizando la abundante documentación original manuscrita existente y muy concretamente los contratos de obra, que han aportado las fechas de contratación y construcción de las distintas partes y según los diferentes oficios.

Con estos datos hemos elaborado un cronograma que muestra las fases de la construcción del conjunto formado por la Galería, la Botica, el jardín, el Muro de los Nichos y el paso a la Compaña:

- El sector mediodía del Muro de los Nichos se empezó a cimentar y a levantar por tramos entre 1563 y 1564 . Sin embargo, la plataforma de los jardines pensiles y las escaleras de bajada a la huerta en esta parte del Monasterio no se concluyeron hasta 1571.

- Los primeros trabajos de explanación de la Lonja de poniente, el drenaje y la construcción del muro de contención de la Botica se llevaron a cabo entre el otoño de 1564 y la primavera de 1565 . El muro se construyó con contrafuertes, sirviendo de apoyo y cierre al tramo de la Galería que se orienta al sur.

- Este primer tramo de la Galería se proyectó a finales de 1564. Contó con un sótano, una galería dórica al nivel del jardín y otra jónica arquitrabada a la cota de la planta principal del Monasterio, con cuya Torre de la Enfermería se comunicaba por un paso en voladizo. Esta fase de la construcción se acometió a lo largo de 1565 y 1566, concluyéndose en mayo de 1567.

- En 1574, siete años después de acabado el primer tramo de la Galería, se planteó construir un segundo tramo perpendicular al primero para cerrar el jardín por el oeste, al que también se dotó de un espacioso y ventilado sótano abovedado. La cantería de ésta se acabó a mediados de 1578, y la carpintería a finales del mismo año.
- En 1585 se definieron las condiciones para construir el nuevo edificio de la Botica a espaldas del segundo cuerpo de la Galería, cuya construcción se prolongó hasta 1590. Aunque las condiciones preveían que los órdenes y la ornamentación del claustro de la Botica debían ser similares a los de la vecina Galería, se acabaron con mucha mayor sencillez y funcionalidad. Esta obra afectó de nuevo a la contención de las tierras de la Lonja de poniente y al Muro de los Nichos, que hubieron de prolongarse hacia el oeste a lo largo de 1586. Además, en un principio se pensó que el nuevo edificio tuviera una planta en L y se abriera hacia el sur, pero ante la imposibilidad de ampliarlo hacia poniente se decidió cerrar el claustro a mediodía con otro cuerpo. En 1590 el conjunto funcionaba a pleno rendimiento.

- Finalmente, al año siguiente de iniciarse la obra de la Botica se diseñó el paso cubierto a la Compaña, que quedó terminado en 1587. (Tabla 1).

\section{RESULTADOS Y CONCLUSIONES}

La comprobación de las hipótesis conduce a las siguientes conclusiones.

Los grabados de Herrera y Perret no se hicieron a partir de la realidad construida, sino de las trazas del proyecto, y por ello hay una evidente falta de correspondencia entre ambas.

El edificio de la Botica fue el resultado de sucesivas ampliaciones del programa inicial, como también lo fue la Galería de Convalecientes.

A consecuencia de ello, y para adecuarse a lo ya construido, se adoptaron varias decisiones de diseño que se explican por la diacronía entre las fases de construcción de los distintos elementos. Las más importantes se recogen a continuación.

- En las primeras trazas dadas y discutidas en julio de 1564 se pensaba construir una sola escalera de bajada a la huerta frente a la Torre de la Enfermería. La decisión de ampliar a dos adoptada por el rey ese mismo mes acabó suponiendo 
Tabla 1. Pilar Chías y Tomás Abad, 2017: Cronología del trazado y construcción del conjunto de la Botica, la Galería de Convalecientes, el Muro de los Nichos y la Lonja.

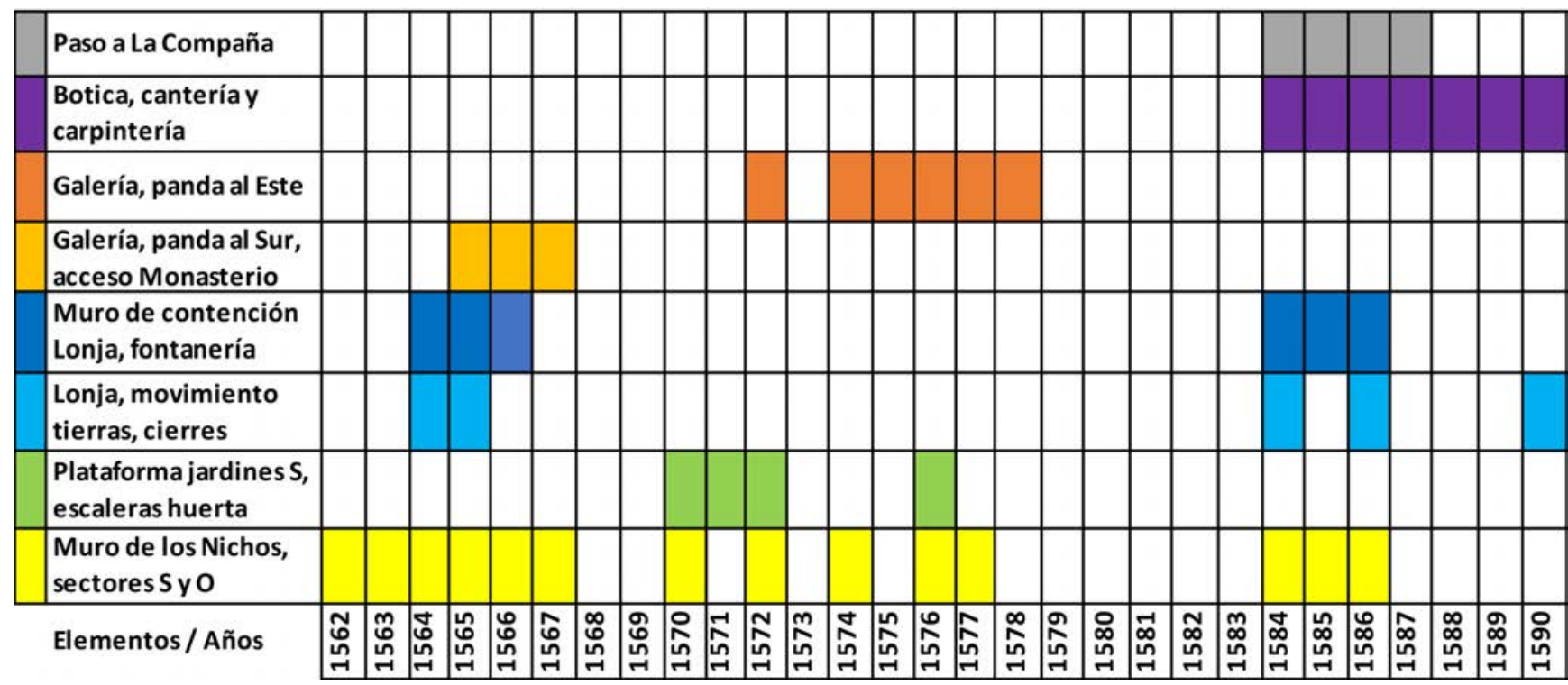

que el pretil de la situada más hacia poniente quedase prácticamente tangente a las basas de las columnas del testero este de la Galería, añadido posteriormente.

- La decisión de ampliar la Galería con un nuevo tramo perpendicular al existente data de 1572, año en el que se dieron también las trazas de su sótano o cantina. El sótano de la Galería orientada al sur y el muro de contención con contrafuertes de las tierras de la Lonja situados bajo ella se habían concluido en 1566 . El encuentro entre ambas bóvedas se resolvió con una bóveda cónica truncada de eje inclinado. El desfase es también la causa de la complejidad de la sección del pilar del ángulo en las galerías superiores.

- La diferencia de longitud de ambos tramos no se debe, como ha apuntado algún historiador, a una razón compositiva ni al deseo de priorizar uno respecto a otro, sino simplemente a la limitación impuesta por el ancho del Jardín -100 pies.

- El que iba a ser muro de cierre del nuevo tramo de la Galería se definió en 1576 con una potencia de 10 pies de ancho y 70 de largo en el nivel de la cantina, y debía trabarse con el existente. Sin embargo, se construyó con un ligero retranqueo para mantener el ancho de las pandas superiores, lo que supuso un quiebro en el muro y la construcción del encuentro entre dos bóvedas de cañón de la misma altura pero distinta luz y ejes paralelos.

- A los sótanos de la Galería y de la Botica se accede por accesos independientes y no están interconectados. Los primeros salen al Jardín por la panda orientada al sur, a través de una escalera en L que corre paralela al muro de contención de la Lonja y que nunca comunicó con la galería alta. Los segundos salían directamente a la huerta a través de una escalera de sillería situada en el interior del último nicho, que fue eliminada hace más de una década; actualmente comunican con la planta baja de la Botica por la escalera más meridional.

- Las conexiones entre Botica y Galería se confiaron, al nivel del jardín, a dos pasos situados en los extremos norte y sur del cuerpo perpendicular a la Lonja; y al nivel de la planta primera del "andar de la casa", por otras dos puertas situadas sobre las anteriores. En el interior de la botica, dos escaleras -septentrional y meridional-facilitan las conexiones verticales hasta bajocubierta (Figura 6a).

- En las "Condiciones como se ha de hacer la obra de la botica", dadas el 6 de mayo de 1585 (35) se especificaba que las pilastras, balaustres y cornisas del claustro de la Botica debían seguir las mismas pautas de diseño que los de la vecina Galería, lo que hubiera supuesto un orden toscano en planta baja y jónico en la primera. Probablemente fueron las limitaciones económicas las que impusieron la solución realizada, mucho más sobria.

- También es probable que las falsas fachadas previstas para ser superpuestas a los lienzos oriental y sur del claustrillo de la Botica no se llevaran a cabo por las mismas razones económicas. Sí que se aplicó, en cambio, este criterio al diseño de la fachada norte del edificio -el que se alza a la Lonja de poniente-, cuya mitad oriental es fingida -la correspondiente al muro de contención de la Galería-, pero cuyo diseño es homogéneo en todo su desarrollo.

- La disposición de las oficinas en planta baja situadas junto a la Lonja impuso un quiebro en los ejes de las pandas septentrionales de la Galería y la Botica, y en el de la arquería de paso a la Compaña, que hubo de resolverse con un conoide esviado.

- También aumentaron las dimensiones previstas inicialmente para ciertos elementos como la anchura de la Lonja oeste -contratándose el cierre en agosto de 1586- y la longitud de los muros de contención de tierras de la Lonja, de la plataforma del Jardín de los Frailes -Muro de los Nichos-y del camino de Robledo de Chavela -adjudicándose la sección perpendicular del Muro de los Nichos en octubre de 1586.

- También hubo de prolongarse la fachada septentrional del conjunto, confiándose la unidad compositiva a falsas ventanas en la parte ciega correspondiente a la Galería.

Respecto a la producción de una planimetría precisa y actualizada -hasta ahora inexistente-, también se han cumplido los objetivos. Ésta ha permitido comprobar tanto las dimensiones reales de diferentes elementos como el incremento sufrido, lo que a su vez ha permitido confirmar las hipótesis 
planteadas sobre la cronología y las fases de construcción del edificio.

Como resultado del proceso también se están llevado a cabo análisis formales, funcionales y constructivos del edificio en relación con los adyacentes.

\section{AGRADECIMIENTOS}

Agradecemos a Patrimonio Nacional, a la Comunidad Agustina del Monasterio y al Real Centro Universitario Escorial - María Cristina las facilidades que nos han brindado para desarrollar esta investigación.

\section{REFERENCIAS}

(1) Lhermite, J. (1602). Le Passetemps, Bibliothèque royale de Belgique, Bruxelles, Manuscripti historici $\mathrm{n}^{0} 17$. Se cita por la ed. de 1890-1896: Ruelens, C., Ouverleaux, E., Petit, J. (Eds.), Le Passetemps, vol. II, (pp. 71-72). Gent, Belgique: Antwerpsche Bibliophilen.

(2) Andrés, G. de (1958). Inventario de documentos sobre la construcción y ornato del Monasterio del Escorial existentes en el Archivo de su Real Biblioteca (Anejo de Archivo Español de Arte). Madrid: CSIC.

(3) Chueca Goitia, F. (1981). El proceso proyectivo del Monasterio del Escorial. Arquitectura, 231: 46-53.

(4) Kubler, G. (1982). Building the Escorial. Princeton, New Jersey: Princeton University Press.

(5) Cervera Vera, L. (1986). Conjuntos y caminos en torno al Monasterio de San Lorenzo el Real. En Población y Monasterio - El Entorno, IV Centenario del Monasterio de El Escorial, (pp. 37-64). Madrid: Ministerio de Obras Públicas.

(6) Bustamante, A. (1994). La octava maravilla del mundo (Estudio histórico sobre El Escorial de Felipe II). Madrid: Editorial Alpuerto.

(7) Íñiguez, J.L. (1965). Las Trazas del Monasterio de San Lorenzo de El Escorial, (Discurso de ingreso). Madrid: Real Academia de Bellas Artes de San Fernando.

(8) Zuazo, S. (1948). Los orígenes arquitectónicos del Real Monasterio de San Lorenzo de El Escorial. Madrid: Real Academia de Bellas Artes de San Fernando.

(9) Lorente Junquera, M. (1944). La Galería de Convalecientes, obra de Juan de Herrera. Archivo Español de Arte, 63: 137-147.

(10) Chías, P. (2014). Fincas y cazaderos reales en el entorno del Monasterio de San Lorenzo de El Escorial: tradición medieval e influencia flamenca. Revista EGA, 23: 46-53, doi: http://dx.doi.org/10.4995/ega.2014.2171.

(11) Chías, P. y Abad, T. (2013). Terrestrial and Aerial Ground-penetrating Radar in use for the Architectural Researches: Ancient 16th Century Water Supply and Drainage at the Monastery of El Escorial (Madrid, Spain). ISPRS International Archives of the Photogrammetry, Remote Sensing and Spatial Information Sciences, XL-5/W2: 177-182, doi: http:// dx.doi.org/10.5194/isprsarchives-XL-5-W2-177-2013.

(12) Chías, P. y Abad, T. (2014). La construcción del entorno del Monasterio de San Lorenzo de El Escorial. Agua, territorio y paisaje. Informes de la Construcción, 66 (536): 1-12, doi: http://dx.doi.org/10.3989/ic.14.027.

(13) Chías, P. y Abad, T. (2016). La transformación de la topografía y del paisaje en la construcción del Monasterio de El Escorial. Informes de la Construcción, 68 (543): 1-12, doi: http://dx.doi.org/10.3989/ic.15.142.

(14) Archivo General de Palacio, leg. 1792, fo 392.

(15) Almela, J.A. (1594). Descripción de la Octava maravilla de el Mundo que es la excellente y Sancta casa de sant laurencio el Real Monasterio de frailes hieronimos y Collegio de los mesmos y seminario de letras humanas y sepultura de Reyes y Casa de recogimiento y descanso después de los trabajos de el Gobierno... Biblioteca Nacional de España, Madrid, Ms. 1724, ff. 98v, 183r-188r, 212r-217r.

(16) Herrera, J. de (1589). Sumario. Biblioteca Nacional de España, Madrid, Secc. Raros, R/35254,ff. 12-12v.

(17) Chías, P. y Abad, T. (2017). Modelos, plantillas, trazas y monteas en los contratos para la construcción del Monasterio de San Lorenzo de El Escorial. Informes de la Construcción, 69 (547), doi: http://dx.doi.org/10.3989/id55077.

(18) San Jerónimo, J. de (1591). Libro de memorias deste Monasterio de San Lorenzo El Real. Real Biblioteca del Monasterio de San Lorenzo del Escorial, Ms. K-1-7, fo 370.

(19) Sigüenza, J. de (1604). La Fundación del Monasterio de El Escorial, (Tercera parte de la Historia de la Orden de San Gerónimo). Real Biblioteca del Monasterio de San Lorenzo del Escorial, Ms. \&-II-22, pp. 706-854.

(20) Wadsworth, J. (1630). The Present Estate of Spain or A true relation of some remarkable things touching the Court, and Government of Spayne ... Imprinted at London by A.M. for Ambrose Rutherdon, at his Shop at the signe of the Bull head in Pauls Church, pp. 11 y 14-15.

(21) Fanshawe, A. (1665). Memoirs of Lay Fanshawe wife of the Right Hon. Sir Richard Fanshawe, Bart. Ambassador from Charles the Second to the Court of Madrid in 1665. London: S. and R. Bentley, p. 157.

(22) Ponz, A. (1777). Viage de España, o Cartas, en que se da noticia de las cosas mas apreciables, y dignas de saberse que hay en ella ... Madrid. MDCCLXXVII. Por D. Joachin Ibarra, Impresor de Cámara de S.M. Se hallará en la librería de Esparza, en la Puerta del Sol, vol. II, pp. 172 y 234-237.

(23) Álvarez, F. (1843). Descripción del Monasterio y Palacio de San Lorenzo, Casa del Príncipe, y demás notable que encierra bajo el aspecto histórico, literario y artístico el Real Sitio del Escorial, para uso de los viageros y curiosos que lo visiten. Madrid: Imprenta de Vicente Lalama, p. 220.

(24) Ford, R. (1845). A Handbook for travellers in Spain and readers at home. London: John Murray, vol. II, p. 819.

(25) Quevedo, J. de (1849). Historia del Real Monasterio de San Lorenzo, llamado comúnmente del Escorial, desde su origen y fundación hasta fin del año 1848. Y descripción de las bellezas artísticas y literarias que contiene. Madrid: Establecimiento Tipográfico de Mellado, p. 348.

(26) Rotondo, A. (1863). Historia descriptiva, artística y pintoresca del Real Monasterio de San Lorenzo, vulgarmente llamado del Escorial. Madrid: Eusebio Aguado, Impresor de Cámara de S.M. y de su Real Casa, pp. 213-214. 
(27) Bermejo, D. (1820). Descripción artística del Real Monasterio de S. Lorenzo del Escorial y sus preciosidades después de la invasión de los franceses; Madrid: Imprenta de Doña Rosa Sanz, pp. 336-341.

(28) Ramírez y La Guardia, L. (1874). Visita a la Octava Maravilla del mundo. Guía del viajero en San Lorenzo del Escorial. Descripción concuriosísimos y minuciosos datos. Madrid: Imprenta a cargo de Gregorio Juste, p. 43.

(29) Chías, P. (2015). La Botica del Monasterio de San Lorenzo el Real de El Escorial. Una visión desde la arquitectura. En A. Gomis y R. Rodríguez Nozal (eds.), De la Botica de El Escorial a la industria farmacéutica: en torno al medicamento, (pp. 23-66). Alcalá de Henares, Madrid: Publicaciones de la Universidad de Alcalá.

(30) Chías, P. (2016). La iconografía del Monasterio de El Escorial: Tradición e innovación en cuatro siglos de imágenes impresas. Revista EGA no 28: 32-43, doi: http://dx.doi.org/10.4995/ega.2016.6046.

(31) Herrera, J. de (1589). Sumario. Biblioteca Nacional de España, Madrid, Secc. Raros, R/35254, fo 25v.

(32) Chías, P., Abad, T., Echeverría, E., Miguel, M. de y Llorente, P. (2017). Underground surveying: $16^{\text {th }}$ century cellar vaults in the Galería de Convalecientes, Monastery of San Lorenzo del Escorial. The International Archives of the Photogrammetry, Remote Sensing and Spatial Information Systems, XLII-2/W3, doi: https://doi.org/10.5194/isprs-archivesXLII-2-W3-179-2017.

(33) Marías, F. (2001). El Escorial entre dos Academias: Juicios y dibujos. Reales Sitios, 38 (149): 2-19.

(34) Chías, P. (2017). Dos siglos de revitalización en la iconografía del Monasterio de El Escorial, 1600-180o. Revista EGA, 29: 28-37, doi: http://dx.doi.org/10.4995/ega.2017.6691.

(35) Real Biblioteca del Monasterio del Escorial, Doc. IX-28, fo 8. 